\title{
Knowledge and Attitude of Staff Nurses Regarding Palliative Care
}

\author{
Anila G Das ${ }^{1}$, Haseena T A ${ }^{2}$ \\ Assistant Professor, SreeGokulam Nursing College, Venjaramoodu \\ Associate Professor, SreeGokulam Nursing College, Venjaramoodu
}

\begin{abstract}
Palliative care is an emerging area of medicine that aims to improve the quality of life of patients with chronic diseases such as cancer, end stage renal failure, chronic obstructive pulmonary disease and so on. The palliative care team usually consists of nurses, doctors, pharmacists, social workers, spiritual leaders and psychologists. Objectives: To assess the level of knowledge and attitude of staff nurses regarding palliative care, to identify the association between knowledge and attitude regarding palliative care with selected socio-personal variables and to determine the correlation between knowledge and attitude regarding palliative care. Methodology: The research approach used in this study is Quantitative and the Design adopted is descriptive. Sample includes the staff nurses in Sree Gokulam Medical College and Research Foundation, Venjaramoodu and sample size was 200. Sampling Technique used was convenient sampling. Tools include a socio-personal performa, a semi-structured questionnaire to assess the knowledge and FATCOD attitude scale to assess the attitude. Data collection technique was self reporting. Results: The study finding revealed that $20 \%$ of staff nurses have adequate knowledge while majority (69\%)were having moderate knowledge and $11 \%$ were having poor knowledge. Majority of the subjects (79.5\%) were having moderate attitude regarding palliative care, $17.5 \%$ were having adequate attitude while $3 \%$ were having poor attitude. The correlation co-efficient value obtained was 0.272 which suggest a weak positive correlation between knowledge score and attitude score of staff nurses regarding palliative care.
\end{abstract}

Keywords: Knowledge, Attitude, staff nurses, Palliative care

\section{Introduction}

Palliative care is a term derived from Latin word Palliare, "to cloak". Palliative care is a philosophy of care that provides a combination of disease modifying and supportive, compassionate therapies intended to alleviate pain and other symptoms while addressing the emotional, social, cultural, and spiritual needs of patients and families who are experiencing life threatening progressive illness.

Research has indicated that the education of health professionals in end of life care has been limited or nonexisting in nursing and in medicine. Competent and compassionate end of life care is the responsibility of all health professionals. Each discipline must determine strategies to educate its students and professionals in palliative care. A 2009 study regarding palliative care in 120 US cancer centres reported that only $23 \%$ of the centres had bed that are dedicated to palliative care. $37 \%$ offered inpatient hospice care and $75 \%$ had a median time of referral to palliative care to the time of death of 30 to 120 days. Research programs and palliative care fellowships were uncommon.

The results of a 2010 study in The New England Journal of Medicine revealed that lung cancer patients receiving palliative care experienced less depression, increased quality of life and survived months longer than those received standard oncologic care.

\section{Background and Need of the Study}

By 2020, the World Health Organization (WHO) estimates that non-communicable diseases (NCDs) will be as prevalent as communicable diseases, which have been the main cause of high morbidity and mortality among the world population. It is a major undertaking for health systems worldwide to deliver appropriate palliative care. Many countries have experienced dramatic improvements in population life expectancy. The proportion of elderly people, and particularly those over 80 , has increased significantly in recent decades. As populations age, people die in greater numbers after long illnesses from heart disease, cerebrovascular disease including stroke, chronic respiratory disease and respiratory infections, and cancer. Palliative care is concerned both with patients and their families and with the enhancement of quality of life from an early stage in a life-threatening illness.

In a study done in Malappuram District of Kerala, it was found that around $40 \%$ of those people who are dying would have benefited from applying the principles of palliative care in their management. In Kerala, with a population of 32 million and a crude death rate of 6.3 (based on Census 2001) around 80,000 dying patients and their families would be benefited each year. To provide quality care at the end of life or for chronically sick patients, nurses must have good knowledge, attitude and practice about palliative care.

\section{Review of Literature}

A study regarding knowledge, attitude and practice of nurses toward palliative care was conducted in Eastern Ethiopia. The study used a cross sectional descriptive survey and the data was collected with a self-administered questionnaire from 197 nurses. The study revealed that $56 \%$ had good knowledge and $88.3 \%$ of them had favourable attitude towards palliative care. The study showed that there is no significant association between knowledge of palliative care and age, sex and experiences of the nurses ( $\mathrm{P}$ value $>0.05$ ). 


\section{International Journal of Science and Research (IJSR) \\ ISSN (Online): 2319-7064}

Index Copernicus Value (2013): 6.14 | Impact Factor (2014): 5.611

There was a positive correlation between knowledge and attitude regarding palliative care $(\mathrm{r}=.268, \mathrm{p}=.00)$

A quasi experimental study was conducted in 2013 in the paediatric medical ward and ICU at Menoufiya university hospital, Egypt with an aim to evaluate the impact of palliative care education on nurse's knowledge, attitude and practice in care of chronically ill children. Tool of data collection was an interviewing questionnaire sheet which included Socio-demographic Data, Nurses' knowledge; Nurses' attitude and Nurses' experience. Results of the study revealed that less than two thirds $(63.3 \%)$ of nurses have bachelor degree, and none of them gave care for dying children in the past year. Regarding nurses' knowledge, less than one third of them $(30 \%)$ in pre-test correctly know the philosophy of palliative care compared to $60 \%$ in post-test. Also, there were statistically significant difference between pre and post-test relating to nurses' attitude.

A descriptive study was conducted to assess the knowledge and practice of staff nurses on palliative care in selected hospitals of Guwahati city, Assam. A self-administered structured questionnaire was used to collect data from 100 staff nurses. The study revealed that maximum (79\%) have inadequate knowledge, $21 \%$ have moderately adequate knowledge and no one has adequate knowledge on palliative care. According to the levels of practice, maximum $48 \%$ practiced adequately where as $43 \%$ practiced moderately adequate and only $9 \%$ practiced inadequately. The correlation $(\mathrm{r}=0.30)$ indicated that there is a positive correlation between knowledge and practice scores of palliative care by the staff nurses. Further analysis revealed that there is positive correlation between knowledge and practice with all the age group, professional qualification. It was also observed that there is a negative correlation between knowledge and practice of nurses with lowest and highest years of experience selected for this study.

A correlative study in 2011 aimed at identifying the level of knowledge and attitude of nursing students who are the future caretakers of patients with the objectives to assess the level of knowledge of nursing students on palliative care, to identify the attitude of nursing students towards palliative care and to find the correlation between the knowledge and attitude of nursing students. The survey was carried out among 83 third-year Diploma Nursing students by using cluster sampling method from selected nursing schools of Udupi district. The results showed that the majority (51\%) of them was in the age group of 21years and $92 \%$ of them were females. Only $43.4 \%$ of them were aware of the term palliative care. The data showed that $79.5 \%$ of students had poor knowledge $(6.4 \pm 1.64)$ on palliative care and $92.8 \%$ of them had favourable attitude $(56.7 \pm 8.5)$ towards palliative care. A negative correlation existed between knowledge and attitude scores, which was not significant at 0.05 level of significance The chi-square showed a significant association between knowledge and age $(\chi 2=18.52, \mathrm{P}<0.01)$ of the nursing students.

A study was conducted to examine oncology and intensive care nurses' knowledge about palliative care in South-east Iran. Using the Palliative Care Quiz for Nursing (PCQN), 140 oncology and intensive care unit (ICU) nurses' knowledge about palliative care in three hospitals were assessed.In PCQN, the mean score was 7.59 (SD: 2.28). The most correct answers were in the category of management of pain and other symptoms $(46.07 \%)$. The lowest correct answers were in the category of psychosocial and spiritual care.

A study was conducted to examine oncology and intensive care unit nurses' attitudes toward palliative care in Iran. A self-administered questionnaire was used to assess the palliative care attitudes of 140 oncology and ICU nurses from three hospitals. The study revealed that the participants had moderately negative to neutral attitudes toward palliative care $(2.99 \pm 0.29$ out of 5$)$. A significant correlation was found between nurses' attitude towards palliative care and some demographic characteristics including marital status, type of ward, palliative care education, personal study about palliative care, level of education and experience of caring for a dying family member.

In 2012, a descriptive, co-relational study examined nurses' knowledge of end-of-life care and also the relationship between the nurses' knowledge and their characteristics using a convenience sample of 368 Korean registered nurses working in cancer units, general wards and intensive care units of a university health system. Twenty questions of the Palliative Care Quiz for Nursing (PCQN) were used to examine nurses' knowledge of end-of-life care. The mean score on the PCQN was 8.95. Participants who had the endof-life care education $(\mathrm{M}=9.57, \mathrm{SD}=2.19)$ tended to score higher than those without this education $(\mathrm{M}=8.47, \mathrm{SD}=$ $2.34)$ and the difference was statistically significant.

In 2008, a study was conducted to identify residential aged care nurses' current knowledge of palliative care for older residents in need of end-of-life care. It was an analytical study using a validated questionnaire tool - Palliative Care Quiz for Nursing combined with a demographic survey of Registered Nurses and assistants in nursing working in five high care residential aged care facilities in inner city region of Sydney, Australia. The results revealed that the mean score for Registered Nurses was 11.7 (SD 3.1) and for AINs 5.8 (SD 3.3), the difference between scores being significant $(\mathrm{t}=8.7$, df 95, $\mathrm{P}=0.000)$. Misconceptions in palliative care were identified for both the groups of care givers. This research has highlighted the need for ongoing palliative care education for both the groups of primary care givers.

A cross-sectional descriptive survey was conducted in 2007 to determine the knowledge, attitude and practice of physicians and nurses towards palliative care in Lebanon and to assess the need and model for service delivery using self-administered questionnaire. 1873 nurses and 1884 physicians participated in the study. The response rate was $51 \%$ for nurses and $13 \%$ for physicians. Around $93 \%$ of nurses and $96 \%$ of physicians were able to identify the goals of PC. The majority ( $94 \%$ to $99 \%$ ) believed that terminally ill patients and their families should be informed of the diagnosis and prognosis. Only 19\% percent of physicians routinely informed terminally ill patients about their diagnosis.

\section{Volume 4 Issue 11, November 2015}




\section{Objectives}

- To assess the level of knowledge of staff nurses regarding palliative care

- To assess the attitude of staff nurses regarding palliative care

- To identify the association between knowledge regarding palliative careand selected socio-personal variables

- To identify the association between the attitude regarding palliative care and selected socio-personal variables.

- To identify the relationship between knowledge and attitude of staff nurses regarding palliative care

\section{Assumption}

- Nurses may have knowledge on palliative care

- The attitude of staff nurses may vary regarding palliative care

\section{Validity and Reliability}

Content validity was done by 5 experts from the field of nursing. There were 100\%agreements among the experts regarding the item coverage. Internal consistency of the knowledge questionnairewas calculated using split-half method and was found to be 1 .

The FATCOD scale is a standardized tool to assess the attitude of staff nurse regarding palliative care. Reliability of the FATCOD has been established multiple times. The content validity index (CVI) of the FATCOD in 1988 was 1.00 with a computed inter-rater agreement of 0.98 . The CVI was repeated in 1998 with an inter-rater agreement of 1.

\section{Research design and approach}

- Approach : Quantitative

- Design : Descriptive design

\section{Sampling technique}

- Setting :Sree GokulamMedical College and Research Foundaion,, Venjaramoodu

- Population :Staff nurses

- Sample :Staff nurses from various wards of SreeGokulam Medical College and Research Foundaion,, Venjaramoodu

- Sample Size : 200

- Sampling Technique : Convenient sampling

\section{Tools and Techniques}

Tools used were questionnaire on socio-personal data, a semi-structured questionnaire to assess the knowledge regarding palliative care and FATCOD attitude scale to assess the attitude regarding palliative care. Data collection technique was self reporting.

\section{Analysis and Interpretation}

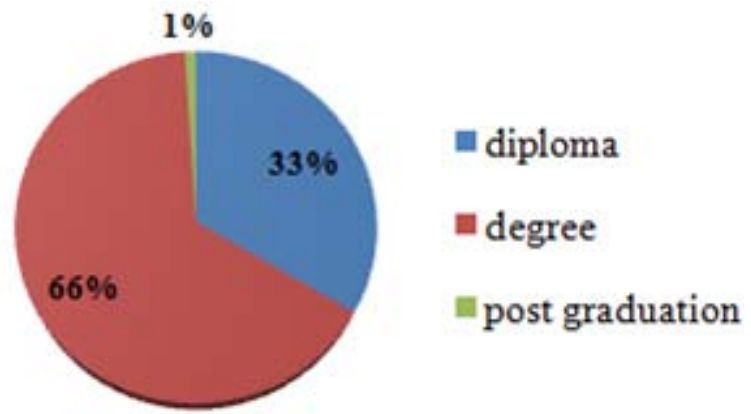

Figure 1: Pie diagram representing the distribution of subjects based on qualification

Figure 1 illustrates that majority, (66\%) of the subjects were nursing graduates, $33 \%$ subjects were qualified with diploma in nursing and only $1 \%$ was post-graduate nurse

Table 1: Frequency distribution of subjects based on years

\begin{tabular}{lcc}
\multicolumn{3}{c}{ of experience } \\
\multicolumn{1}{c}{ (Yrs) } & $\begin{array}{c}\text { Frequency } \\
\text { (f) }\end{array}$ & $\begin{array}{c}\text { Percentage } \\
(\%)\end{array}$ \\
\hline 0-2 yrs & 95 & 47.5 \\
$2-4$ yrs & 85 & 42.5 \\
$4-6$ yrs & 11 & 5.5 \\
Above & 9 & 4.5 \\
6 yrs & &
\end{tabular}

It is evident from Table 1 that, nearly half of subjects $(47.5 \%)$ were having $0-2$ years of experience, $42.5 \%$ were havingexperience between 2-4 years, 5.5\% were havingexperience between $4-6$ years and $4.5 \%$ had experience of more than 6 years.

Table 2: Distribution of subjects based on knowledge score $(n=200)$

\begin{tabular}{llc}
\hline $\begin{array}{c}\text { Knowledge } \\
\text { Score }\end{array}$ & $\begin{array}{c}\text { Frequency } \\
\text { (f) }\end{array}$ & $\begin{array}{c}\text { Percentage } \\
(\%)\end{array}$ \\
\hline Poor & 22 & 11 \\
Moderate & 138 & 69 \\
Adequate & 40 & 20 \\
\hline
\end{tabular}

Table 2 shows that more than half of the subjects $(69 \%)$ were having moderate knowledge, $20 \%$ have adequate knowledge and only $11 \%$ were having poor knowledge regarding palliative care.

Table 3: Distribution of subjects based on attitude score

\begin{tabular}{lcc}
\multicolumn{3}{c}{$(\mathrm{n}=200)$} \\
\hline Attitude & $\begin{array}{c}\text { Frequency } \\
\text { (f) }\end{array}$ & $\begin{array}{c}\text { Percentage } \\
\text { (\%) }\end{array}$ \\
\hline Poor & 6 & 3 \\
Moderate & 159 & 79.5 \\
Adequate & 35 & 17.5 \\
\hline
\end{tabular}

Table 3 reveals that majority of the subjects $(79.5 \%)$ were having moderate attitude regarding palliative care, $17.5 \%$ 


\section{International Journal of Science and Research (IJSR) \\ ISSN (Online): 2319-7064}

Index Copernicus Value (2013): 6.14 | Impact Factor (2014): 5.611

had adequate attitude and only $3 \%$ had poor attitude toward palliative care.

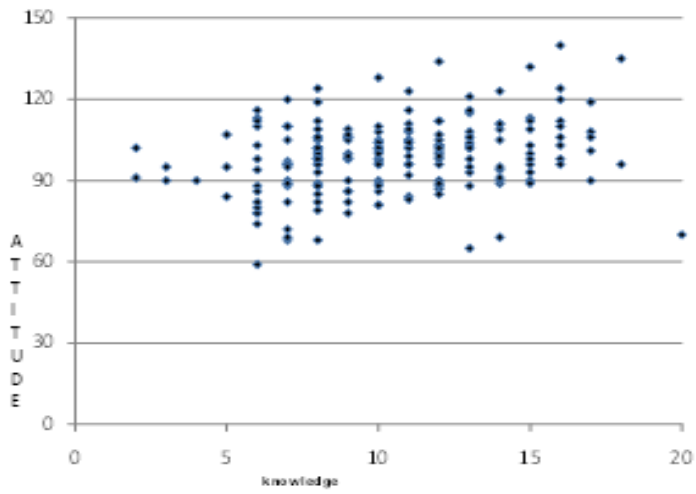

Figure 2: Scattered diagram showing correlation between knowledge and attitude

Figure 2 shows that there is a weak positive correlation between knowledge score and attitude score of staff nurses regarding palliative care.

\section{Limitations of study}

- This study was limited to staff nurses working in Sree Gokulam Medical College.

- The study was limited to a sample size of 200 subjects.

\section{Discussions}

From the present study findings, it is revealed that more than half of the subjects $(69 \%)$ had moderate knowledge, $(20 \%)$ had adequate and only (11\%) have poor knowledge regarding palliative care. The study findings are inconsistent with the study findings of Begum Sorifa, Khanammosphea (2015) on knowledge and practice of staff nurses on palliative care in selected hospitals of Guwahati city, Assam. The study revealed that maximum (79\%) have inadequate knowledge and $21 \%$ have moderately adequate knowledge.

From the present study findings it is revealed that among 200 subjects majority (79.5\%) have moderate attitude regarding palliative care and $(17.5 \%)$ had adequate attitude and only $(3 \%)$ had poor attitude regarding palliative care. When compared with a study regarding assessment of knowledge, attitude and practices and associated factors towards palliative care among nurses working in selected hospitals, Addids Abada, Ethiopia, the result revealed that (30.5\%) had good knowledge and (76\%) had favourable attitude towards palliative care.

The present study shows that there is a weak positive correlation between knowledge and attitude of staff nurses on palliative care. The finding are inconsistent with the findings of another study on knowledge and attitude towards palliative care among multinational nurses conducted by Abudari etal, which revealed that staff nurses had moderate level of attitude but had knowledge deficit regarding palliative care.

\section{Nursing Implications}

\section{Nursing Practice}

- Educational programs should be conducted by the nursing personnel both in the hospital and community on palliative care

\section{Nursing Education}

- Incurriculum, due importance should be given to palliative care and students should be motivated to gain more knowledge and to develop a positive attitude towards palliative care.

- Palliative care home visits should be arranged as a part of student curriculum to provide first hand experience

\section{Nursing Administration}

- The nurse administrator should plan and organize educational programmes for nursing personnel on palliative care.

- Nurse administrators must render due attention in developing and maintaining palliative care wards.

\section{Nursing Research}

- More explorations can be done on methods to improve the quality of palliative care.

\section{Conclusion}

The present study assessed the knowledge and attitude of staff nurses on palliative care. Study recommends that attention should be given towards palliative care by the National health policy makers and must be incorporated in nursing education curriculum especially in undergraduate nursing studies.

\section{Acknowledgement}

The authors express their sincere thanks to respected Principal Lt. Col. Meera K Pillai, HOD, Dpt.ofMental Health Nursing, Sree Gokulam Nursing College, Sree Gokulam Medical College and Research Foundation, Trivandrum for her kind support and guidance throughout the study.

\section{References}

[1] World Health Organization (WHO): WHO definition of palliative care. 2006. Available from: http://www.who.int/cancer/palliative/definition/en/

[2] Meaza D, Worku Z, Knowledge, Attitude and Practice of nurses towards palliative care in HararNational Regional State, Eastern Ethiopia available from $\mathrm{http} / /$ :www.academia.edu

[3] El Nagar S, Lawend J Impact of Palliative Care Education on Nurses' Knowledge, Attitude and Experience Regarding Care of Chronically Ill ChildrenJournal of Natural Sciences Research volume3, no.11, 2013. available from www.iiste.org

[4] Begum Sorifa,KhanamMosphea Knowledge and Practice of Staff Nurses on Palliative CareKhanamMosphea, IJHRMLP, Vol: 01 No: 02 June, 2015. 
[5] SujaKarkada, Baby S Nayak, and Malathi "Awareness of Palliative Care Among Diploma Nursing Students"Indian J Palliat Care. 2011 Jan-Apr;17(1):2023.

[6] Iranmanesh ,Razban , Tirgari B , Zahra G Nurses' knowledge about palliative care in Southeast IranPalliat Support Care. 2014 Jun;12(3):203-10.

[7] Razban F, Iranmanesh S, RafieiHNurses' attitudes toward palliative care in south-east IranInt J PalliatNurs. 2013 Aug;19(8):403-10

[8] Choi M1, Lee J, Kim SS, Kim D, Kim HNurses' knowledge about end-of-life care: where are we?JContin EducNurs. 2012 Aug;43(8):379-84.

[9] Ronaldson S, Hayes L, Carey M, Aggar CA study of nurses' knowledge of a palliative approach in residential aged care facilitiesInt J Older People Nurs. 2008 Dec;3(4):258-67.

[10]Abu-SaadHuijer H, DimassiH.Palliative care in Lebanon: knowledge, attitudes and practices of physicians and nursesJ Med Liban. 2007 JulSep;55(3):121-8.

\section{Author Profile}

Mrs. Anila G Das, MSc (N) completed her Masters in Nursing in Medical-Surgical Nursing Specialty (CardioVascular and Thoracic Nursing) from Govt. College of Nursing, Medical College, Trivandrum and was graduated from CSI College of Nursing, Karakonam. She is currently working as Assistant Professor in Department of Medical-Surgical Nursing, Sree Gokulam Nursing College, Sree Gokulam Medical College and Research Foundation, Venjaramoodu, Trivandrum, Kerala. She has published various research papers amenable to nursing in International Journals.

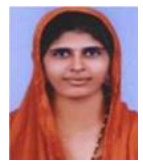

Mrs. Mrs. Haseena T A, MSc (N) is currently working as Associate Professor and Head of the Department, Medical Surgical Nursing, Sree Gokulam Nursing College, Trivandrum. She completed her Bachelors in Nursing from Sree Balaji College of Nursing and received her Master's in Nursing with first rank from Meenakshi College of Nursing, Chennai. Currently, she is doing $\mathrm{PhD}$ under INC, National Consortium. She has been a resource person for various national conferences and also has published research papers in national and international journals. 